\title{
Modeling and Measurements of Heat Release Distributions in Dual-Mode Scramjet Combustor
}

\author{
Lu TIAN ${ }^{1}$, Lihong $\mathrm{CHEN}^{2}$, Qiang $\mathrm{CHEN}^{3}$, Fei $\mathrm{LI}^{4}$, Xinyu CHANG ${ }^{5}$ \\ State Key Lab of High Temperature Gas Dynamics, Institute of Mechanics, Chinese Academy of Sciences, \\ Beijing, China, 100190
}

\begin{abstract}
To better evaluate the performance of dual-mode scramjet combustor, the axis distribution of heat release must be predicted accurately. Current work is based on a modified 1-D model assisted by measurements acquired in a dual-mode combustor on directconnected scramjet facility. $\mathrm{CH}^{*}$ images have been employed to study the combustion stabilization modes and further determine the start position of heat release for 1-D model. The heat release distributions of multi-ports and sing-port injections have been numerically investigated by 1-D model and validated by TDLAS measurements. The results show that heat release distributions depend on the arrangements of injections and flameholders. Close multi-ports injections bring higher combustion efficiency but further propagation of precombustion shock. On the contrary, sing-port injection with pure three-dimensional flowfield can obtain both high efficiency and more stable pre-combustion shock.
\end{abstract}

$\begin{aligned} A & =\text { geometric area of the duct } \\ D & =\text { hydraulic diameter } \\ \dot{m} & =\text { mass flow rate }\end{aligned}$

Subscripts

in $=$ conditions at the entry of isolator $\max =$ the maximum value

Nomenclature
\[ \begin{array}{cl}C_{f} & =\text { friction coefficient } \\ C_{p} & =\text { specific heat capacity } \\ M W & =\text { mass molecular weight }\end{array} \]

$\min =$ the minimum value

$0=$ total or stagnation conditions

\section{Introduction}

$\mathrm{D}$ UAL mode scramjet engines can operate on a wide range of inlet conditions and fulfill the necessity of advancing hypersonic systems. The reliable design depends on accurate modeling of heat release in the combustor. The axis distribution of heat release determines engine parameters along the flowpath and further affects engine states such as ram-scram transition.

However, there are myriads of coupling phenomena in dual-mode combustor, such as the establishment of thermal throat and strong interaction between chemical reaction and turbulence. Thus full-fidelity modeling is not advisable for preliminary design where a large number of calculations are needed. Due to the high efficiency and convenience, quasi-one-dimensional analysis model is preferred.

Thus, the objective of this work is to obtain a reliable modeling method to study the heat release distributions in dual-mode scramjet combustor and then to validate by faithful measurements. As original 1-D methods ${ }^{1-2}$ lack mechanism to simulate back pressure match and the pre-combustion shock model is limited ${ }^{3}$, the authors use modified 1-D method simulating interaction between heat release and pre-combustion shock and handling more cases where Billig's model fades.

In current study, the heat release distribution is obtained by comparison of numerical 1-D pressure distribution with experimental one. Experiments are conducted in a dual-mode combustor on direct-connected scramjet facility

\footnotetext{
${ }^{1}$ Graduate Research Assistant, Institute of Mechanics, CAS, email: tianlu@imech.ac.cn.

${ }^{2}$ Professor, Institute of Mechanics, CAS, email: lhchen@imech.ac.cn. AIAA Member.

${ }^{3}$ Assistant Professor, Institute of Mechanics, CAS, email: chenqiang@imech.ac.cn.

${ }^{4}$ Assistant Professor, Institute of Mechanics, CAS, email: feili@imech.ac.cn.

${ }^{5}$ Professor, Institute of Mechanics, CAS, email: xychang@imech.ac.cn. AIAA Member.
} 
with $\mathrm{CH}^{*}$ imaging and a multi-channel Tunable Diode Laser Absorption Spectroscopy (TDLAS) system. $\mathrm{CH}^{*}$ images as a maker of local heat release are used to study flame front of dual-mode combustion and find the start position of heat release for 1-D model. A TDLAS system is employed to validate the reliability of 1-D results by measuring flow parameters in the combustor.

\section{Method of Modeling and Measurements}

\section{A. Quasi-One-Dimensional Analysis Model}

The modified 1-D analysis method employs an iterative mechanism of back pressure match in the dual-mode combustor. The start of iterations depends on whether the flow will be thermally choked without pre-combustion shock. The obtained parameters along the flowpath determine engine states and the accomplishment of calculation. Figure 1 shows the schematic for process of the 1-D method.

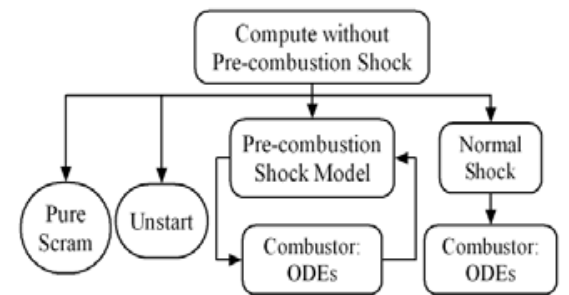

Figure 1. Schematic for process of modified 1-D method

1. Combustor: Governing Equations

Parameters along the combustor are calculated by a series of ODEs similar to previous works ${ }^{2}$. The differential forms of governing equations with assumptions of steady state, quasi-one-dimension and perfect gas are listed here.

Continuity

$$
\frac{1}{\dot{m}} \frac{d \dot{m}}{d x}=\frac{1}{\rho} \frac{d \rho}{d x}+\frac{1}{U} \frac{d U}{d x}+\frac{1}{A} \frac{d A}{d x}
$$

Momentum

Energy

$$
\frac{1}{p} \frac{d p}{d x}+\gamma M a^{2}\left(\frac{1}{U} \frac{d U}{d x}+\frac{2 C_{f}}{D}+\frac{1}{\dot{m}} \frac{d \dot{m}}{d x}\right)=0
$$

$$
\frac{1}{T} \frac{d T}{d x}+\frac{(\gamma-1) M a^{2}}{U} \frac{d U}{d x}-\left(1+\frac{\gamma-1}{2} M a^{2}\right) \frac{\overline{C_{p 0}}}{\overline{C_{p} T_{0}}} \frac{d T_{0}}{d x}
$$

Equation of State

$$
\frac{1}{p} \frac{d p}{d x}=\frac{1}{\rho} \frac{d \rho}{d x}+\frac{1}{T} \frac{d T}{d x}-\frac{1}{\overline{M W}} \frac{d \overline{M W}}{d x}
$$

Mach number Definition

$$
\frac{d U}{U}=\frac{d M a}{M a}+\frac{1}{2} \frac{d T}{T}
$$

Isentropic Flow Relation

$$
\frac{d p_{0}}{p_{0}}=\frac{d p}{p}+\frac{\gamma M a^{2}}{\left(1+\frac{\gamma-1}{2} M a^{2}\right)} \frac{d M a}{M a}
$$

Equation of Entropy Change

$$
\frac{d s}{c_{p}}=\frac{d T}{T}-\frac{\gamma-1}{\gamma} \frac{d p}{p}
$$

Seven parameters, that are total pressure $p_{0}$, static pressure $p$, static temperature $T$, Mach number $M a$, density $\rho$, velocity $U$, and specific entropy s, can be obtained directly. And this stiff equation set is solved by Matlab ODE15s. Besides, equilibrium chemistry with single step is chosen for the energy term. 


\section{Pre-combustion Shock Model}

In the present work, two pre-combustion shock models are adopted. Except for Billig's shock train model ${ }^{3}$, “ $\mathrm{X}$ shock" model promoted by the authors has been used.

Figure 2 depicts the sketch and control volume of "X-shock" model. It was inspired from experimental schlieren images and calculated by two set of oblique shock wave equations. To ensure the closure of calculation and the necessity for 1-D analysis downstream, the deviation angles after the first and second shock pair are assumed to be the same. An average process has been conducted after the control volume of "X-shock" based on averaged mass flow rate and pressure.

The length of pre-combustion shock $L_{s}$ has been modified by data from direct-connected combustion experiments, and the form of the new curvefit can be written as Eq. (8).

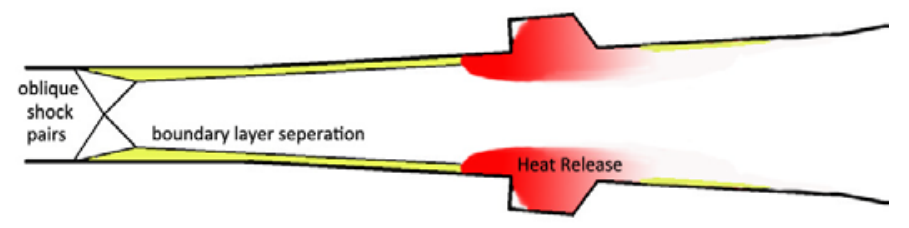

a)

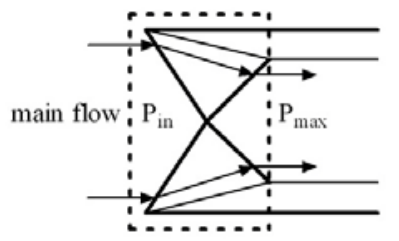

b)

Figure 2. Sketch and control volume of "X-shock" model

$$
\frac{L_{s}}{H}=\frac{\sqrt{\frac{\theta}{H}}}{\sqrt[4]{\operatorname{Re}_{\theta}}} \cdot \frac{\left\{100\left(\frac{p_{\max }}{p_{\text {in }}}-1\right)+350\left(\frac{p_{\max }}{p_{\text {in }}}-1\right)^{2}\right\}}{\left(M a_{i n}^{2}-1\right)}
$$

where $H$ represents the height of isolator, and $R e_{\theta}$ represents the Reynolds number obtained according to momentum thickness $\theta$ using Prandtl analogy.

\section{B. Facilities and Measurements}

The experiments used in this work were performed in a dual-mode ramjet/scramjet combustor on the directconnected facility. The facility using the method of burning hydrogen and adding oxygen provides vitiated air with Mach number of 2.5 and 1.8 respectively. The test section, made by stainless, is sketched in Fig.3a. The constantarea isolator with the cross section of 85 by $40 \mathrm{~mm}$ is followed by with two diverging ducts with angles of 1.5 deg and 3.0 deg, respectively.

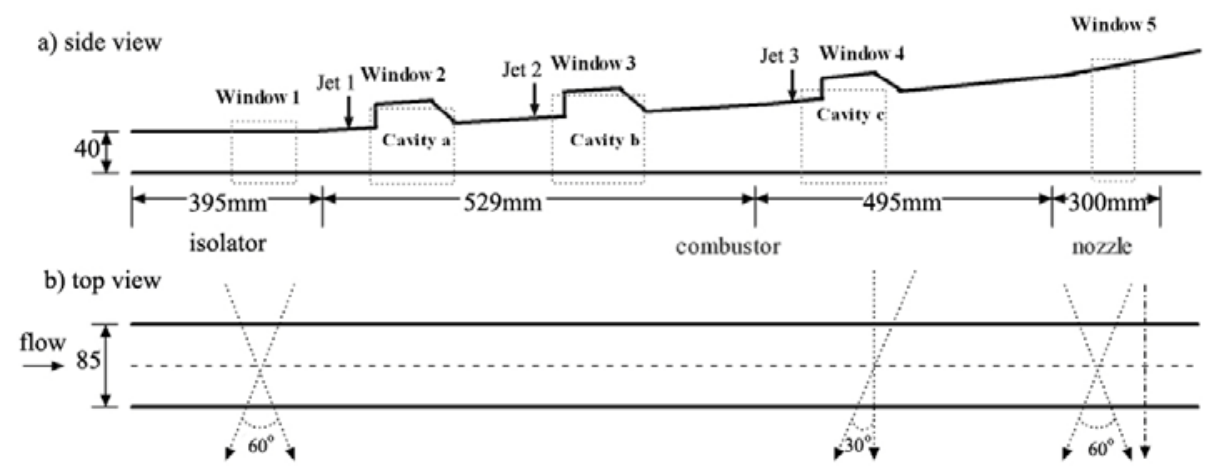

Figure 3. a) Schematic of direct-connected scramjet test facility b) and arrangement of laser beams for TDLAS

Three removable wall injections with cavities downstream are available in the dual-mode combustor. Roomtemperature fuel was injected sonically through parallel $7 \times \Phi 1.2 \mathrm{~mm}$ multi-ports located $60 \mathrm{~mm}$ upstream the leading edge of each cavity used. Whereas, when a single 3 -mm-diam port was implemented $550 \mathrm{~mm}$ downstream of the isolator entry, cavity a was removed and a small amount of fuel was injected from parallel Jet 3 upstream cavity c.

To better analysis the heat release distribution along the duct, TDLAS systems and $\mathrm{CH}^{*}$ imaging were arranged at quartz windows shown in Fig.3. $\mathrm{CH}^{*}$ luminosity images were taken at window 2 using a Basler camera with a $430 \pm 10 \mathrm{~nm}$ bandpass interference filter. TDLAS systems were arranged as shown in Fig.3b.

For experiments with multi-ports injections, a single channel TDLAS (dot dash line in Figure 3b) was adopted vertical scanning at the combustor exit (window 5). For experiments with a main sing-port injection, a multichannel 
TDLAS system with three scanning pairs was used to measure parameters at three different windows (window1: inlet, window4: combustor and window5: exit) simultaneously. The technique of TDLAS is based on the absorption spectroscopy of water vapor and the mechanism of Doppler shift. Besides, direct absorption strategy was chosen with implementing a so-called two-wavelength TDLAS ${ }^{4}$.

\section{Results and Discussion}

The investigations of the current study are divided into two parts: analysis of combustion stabilization modes from $\mathrm{CH}^{*}$ images and comparison of 1-D model results to TDLAS measurements on heat release distribution.

\section{A. $\mathbf{C H}^{*}$ Imaging--Combustion Stabilization Modes}

Two combustion stabilization modes have been discussed by previous works ${ }^{5}$. Except for oscillating cases, combustion were found to stabilized at a short distance after the injector (jet-wake stabilized) or anchored at the leading edge of cavity shear layer (cavity stabilized). As the stabilization modes influences the start position of heat release, a series of $\mathrm{CH}^{*}$ images are studied to facilitate the calculation of 1-D model below.

Figure 4 compares $\mathrm{CH}^{*}$ images of two different fuel injections with Mach number of 1.8 and 2.5, respectively. The above two images (Fig.4a, 4b) were taken at main flow with Mach number of 1.8. Figure 4b shows experiments with both upstream and cavity floor injections, whereas Fig.4a demonstrates case with only cavity fuel. It can be seen that combustion flame front was anchored at the leading edge of cavity regardless of ways of injections. On the contrary, for main flow with higher Mach number, the jet-wake stabilized combustion (Fig.4c, 4d) can be observed after each injector used.

This could be explained by discrepancy of velocity and temperature in two different modes. Main flow with Mach number of 2.5 has higher total temperature which is crucial for jet-wake stabilization. And the inlet mass flow rate of Mach number of 1.8 is much larger than that of 2.5, thus may need longer distance for fuel-air mixing. Besides, cavity flameholder with relative low speed and radicals renders the flame to stabilize at lower total temperature.

In addition, it is likely that cavity fuel does not influence the combustion stabilization modes. Thus in the 1-D modeling, cavity fuel is added to the upstream fuel for cases with Mach number of 2.5, whereas for Mach number of 1.8 , heat release is assumed to begin at the leading edge of cavity.

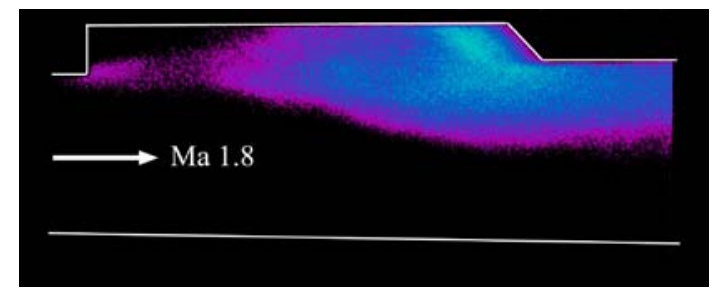

a) Mach 1.8 with cavity fuel

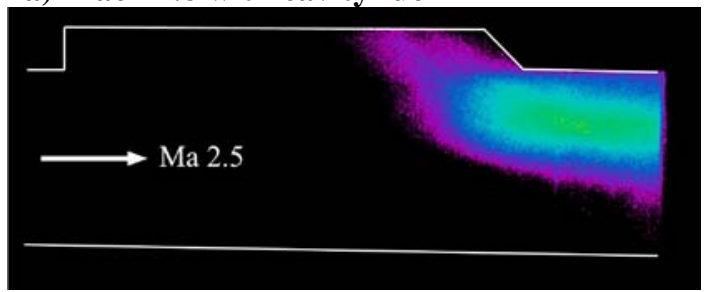

c) Mach 2.5 with cavity fuel

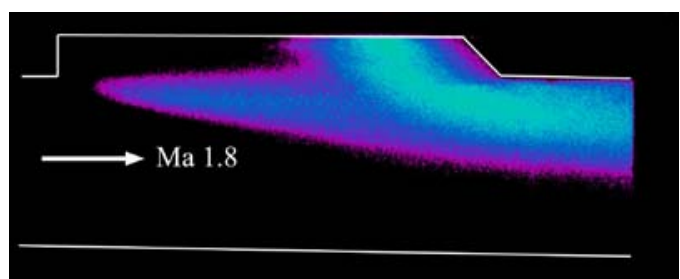

b) Mach 1.8 with upstream and cavity fuel

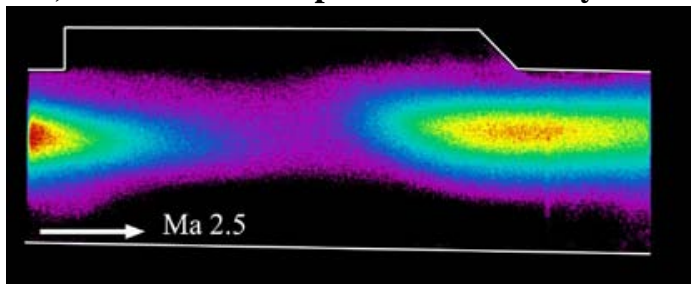

d) Mach 2.5 with upstream and cavity fuel

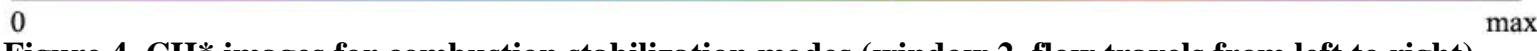

Figure 4. $\mathrm{CH}^{*}$ images for combustion stabilization modes (window 2, flow travels from left to right)

\section{B. TDLAS and 1-D Analysis Model Results}

Here, efforts have been made to compare 1-D results to TDLAS measurements in order to carry out faithful heat release distributions. Present work consists of comparisons of multi-ports injections and a main sing-port injection. Cases analyzed are listed in Table 1 with initial conditions estimated from experiments and results for combustion efficiency. 
Table 1 Conditions and results of cases for 1-D model

\begin{tabular}{ccccccc}
\hline Number & Injections & $\begin{array}{c}\text { Equivalence } \\
\text { ratio }\end{array}$ & $\begin{array}{c}\text { Mach } \\
\text { number }\end{array}$ & $\begin{array}{c}\text { Total } \\
\text { temperature } \\
(\mathrm{K})\end{array}$ & $\begin{array}{c}\text { Mass flow } \\
\text { rate (kg/s) }\end{array}$ & $\begin{array}{c}\text { Combustion } \\
\text { efficiency (\%) }\end{array}$ \\
\hline 1 & Jet1 Jet3 & 0.52 & 2.5 & 1370 & 1.2 & 66.1 \\
\hline 2 & Jet2 Jet3 & 0.52 & 2.5 & 1370 & 1.2 & 82.1 \\
\hline 3 & Jet2 Jet3 & 0.56 & 1.8 & 1000 & 1.6 & 57.6 \\
\hline 4 & Sing-port Jet3 & 0.75 & 2.5 & 1650 & 1.2 & 80 \\
\hline
\end{tabular}

\section{Comparison of Multi-Ports Injection}

Figure 5 compares the experimental data of case 1 with numerical data generated using quasi-one-dimensional method. As shown in Fig.5a, two comparatively separated uniform combustion regions, around cavity a and cavity b, are used for 1-D model. The calculated pressure rise with the Billig shock train model agrees well with the experimental one along the whole duct. Figure $5 \mathrm{~b}$ shows the static temperature distribution in the axial direction $\mathrm{x}$. A single scanning laser beam of TDLAS, implemented at the exit of the combustor (window 5 in Fig.3), acquired the both mean and maximum temperature in the vertical direction. Accounting for the fluctuation of the signals in measurements and the simple mechanism of analysis method, the comparison of temperature at the exit is overall desirable. Thus, it testifies the release of energy to some extent.

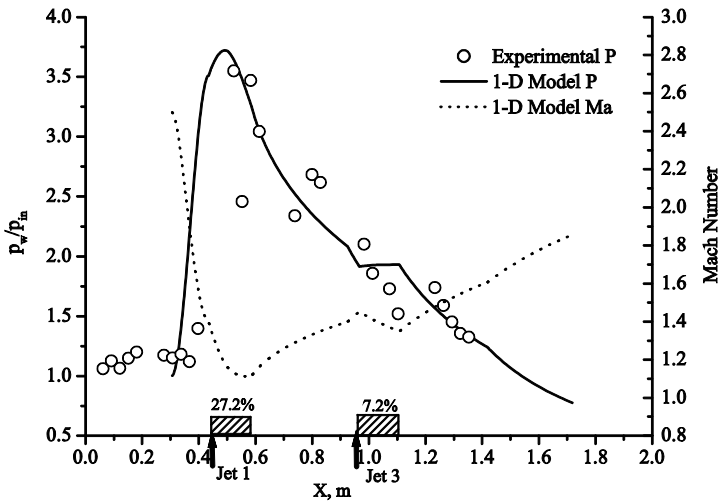

a)

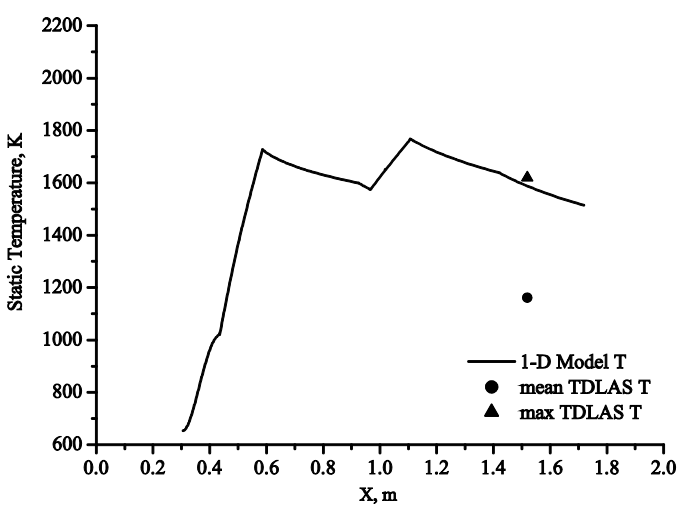

b)

Figure 5. Pressure and temperature comparison of case 1

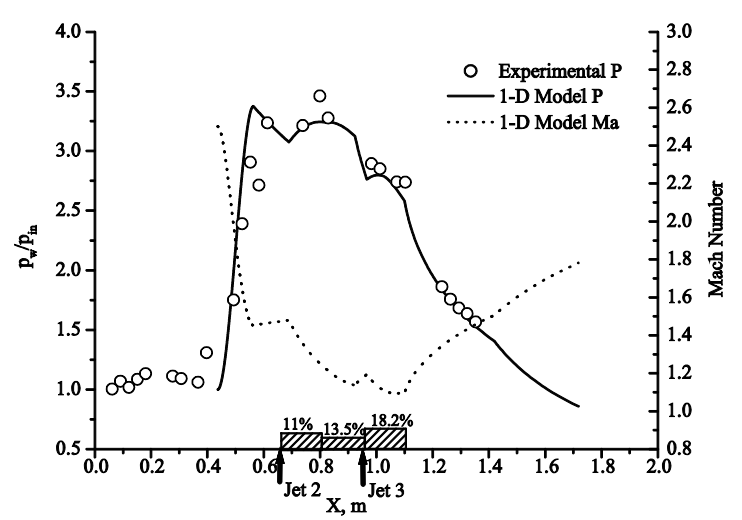

a)

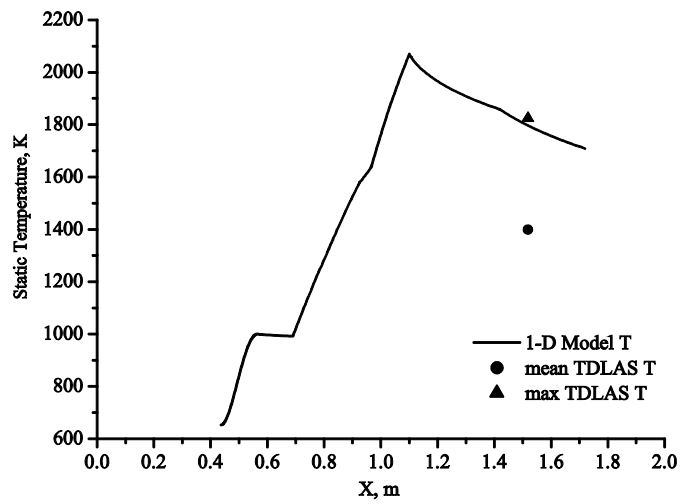

b)

Figure 6. Pressure and temperature comparison of case 2

Figure 6 and Figure 7 compares experimental data with simulation results of case 2 and 3, respectively. Both of the comparisons are satisfied for a reduced-order model. However, the fitted heat release distributions are appeared to be connected rather than separated. This is due to the relative close injections and cavities which are believed to affect energy release. According to Table 1, case 2 has higher combustion efficiency than case 1 due to larger heat 
release. Meanwhile, the comparative low combustion efficiency for case 3 indicates that current model needs to be improved for air flow with lower Mach number.

Further, the "X-shock" model promoted by the authors agrees well with the experimental pressure rise in the precombustion region. This is could be explained that centralized and great amount of heat release and the characteristics of flowfield. Flowfield with characters of two-dimensional and large amount of centralized heat release facilitates the "X-shock" propagating upstream further of the combustion region.

In addition, as shown in Fig.7a, the flow chokes after the rear of cavity c where matches the end of large heat release. Thus, the ram-scram transition is also dependent on the arrangement of injections and cavity flameholding configurations.

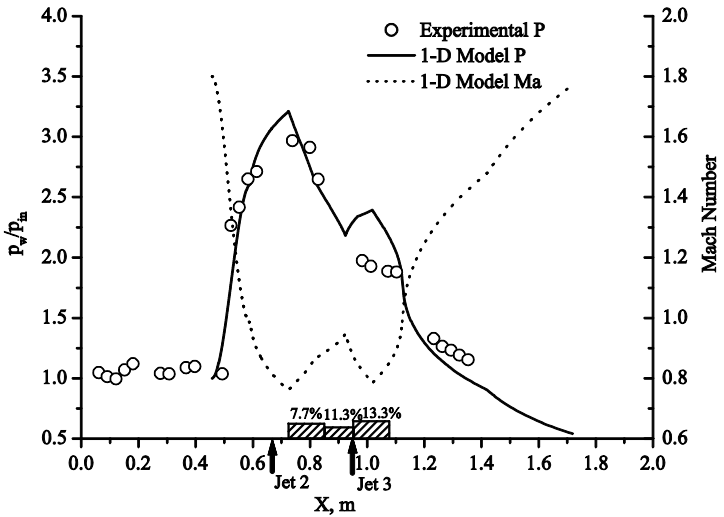

a)

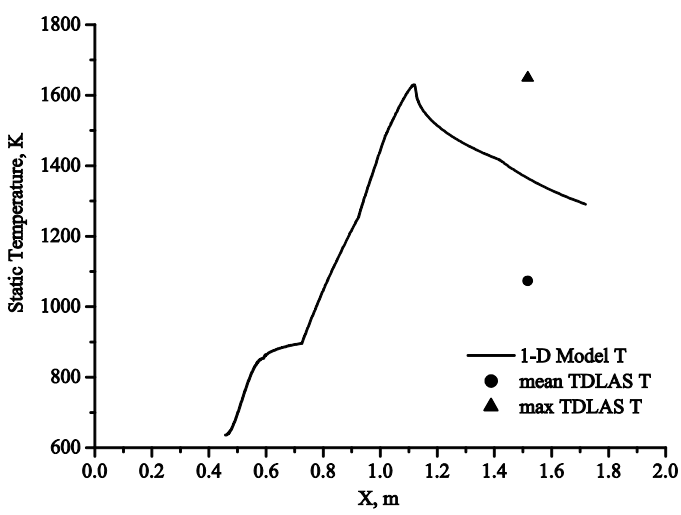

b)

Figure 7. Pressure and temperature comparison of case 3

\section{Comparison of a Single-Port Injection}

Here heat release distribution along the duct will be studied thoroughly in case 4 with a main single-port injection. Comparison has been made between 1-D model results and experimental data acquired from a multi channel TDLAS. In this case, cavity b and c were used, a sing-port was arranged around the position of removed cavity a. A small amount of fuel $\left(\dot{m}_{\text {ussream }} / \dot{m}_{\text {main }}=0.36\right)$ was injected from Jet 3 (shown in Fig.3).

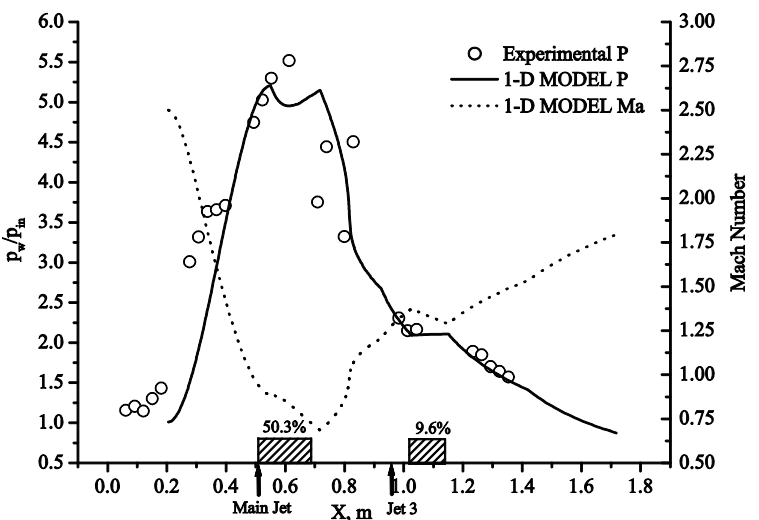

a)

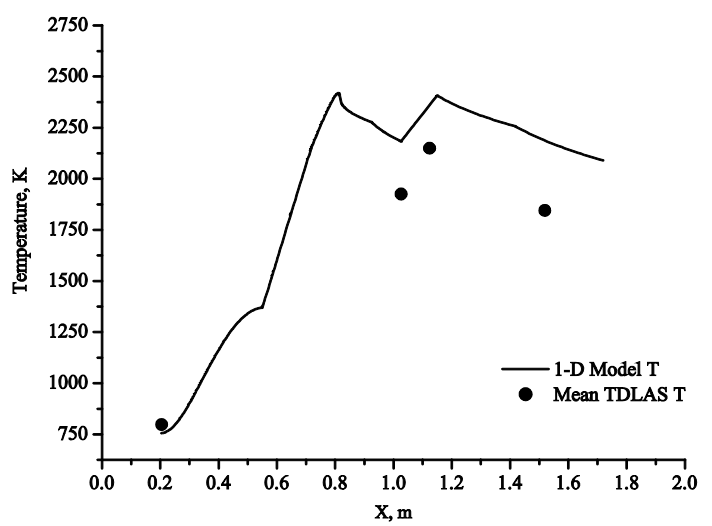

b)

Figure 8. Pressure and temperature comparison of case 4

Figure 8a compares calculated pressure distribution with experimental data, and depicts the corresponding Mach number as well. The overall trend of pressure distribution agrees well. Figure $8 \mathrm{~b}$ uses the parameters obtained from TDLAS measurements at three diverse sections (shown in Fig.3). Four points of mean static temperature are depicted in Fig.8b. Two mean velocity points are drawn in Fig.9.

Firstly, the initial parameters, used in the simulation, tally with the measurements. Then, the similar tendency of temperature validates the utility of simplification for energy release. Finally, the velocity comparisons are also desirable. As the cavity is neglected in current 1-D model, the comparison of velocity in this region cannot be made. 
Thus, the acceptable results at the entry and exit of combustor are more reliable due to the weak heat release and relatively uniform flowfield.

Referring to the combustion efficiency in Table 1, large amount of heat release can be expected after the singleport. But the pre-combustion shock calculated by Billig's model has not been put as further as case 2 and 3 . This could be explained by the three-dimensional flowfield caused by a single port, which facilitates the formation of shock train rather than "X-shock".

In addition, Mach number distribution in Fig.8a shows that ram-scram transition also occurs at the position where large amount of heat release ends (after the rear of cavity b) and this conclusion tallies with that of multi-ports injection.

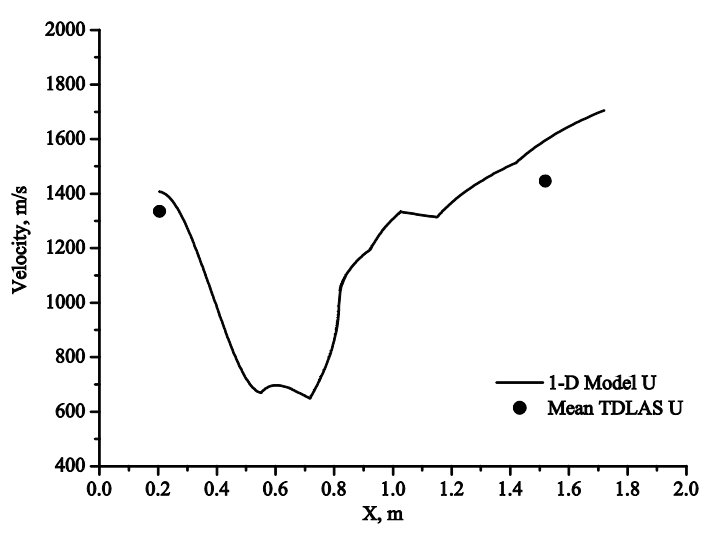

Figure 9. Velocity comparison of case 4

\section{Conclusion}

The dual-mode combustion has been studied thoroughly in both combustion stabilization modes and heat release distributions. $\mathrm{CH}^{*}$ luminosity images shows different stabilization modes occur at disparate inlet flow. Main flow with Mach number of 2.5 demonstrates a trend of jet-wake stabilized, where Mach number of 1.8 belongs to cavity stabilized combustion. Based on the stabilization modes, the heat release distributions of both multi-ports and singleport injections have been researched by comparison of modified 1-D model with experimental data from pressure transducers and TDLAS systems.

For multi-ports injection, close injections generate larger amount of heat release and combustion efficiency. However, care has to been taken for that the relative two-dimensional flowfield facilitates pre-combustion shock propagating upstream and even causes unstart of the engine.

For a main single-port injection, three-dimensional flowfield after the injector renders greater heat release and less propagation of pre-combustion shock. Thus, this kind of arrangement is recommended for current combustor configuration. Besides, as heat release distribution relies on the injections and flameholder configuration, ram-scram transition is also dependent on suitable fuel injection strategy.

In sum, combining the measurements, the modified 1-D model is reliable in estimating heat release distributions. Although more accurate modeling on energy release is expected, the results with iterative mechanism of back pressure match and pre-combustion shock model are desirable.

\section{Acknowledgments}

This research is supported by National Natural Science Foundation of China (11002148).

\section{References}

[1] Curran, E. T., Heiser, W. H., and Pratt, D. T., "Fluid Phenomena in Scramjet Combustion Systems,” Annual Review of Fluid Mechanics, Vol. 28, No.1, 1996, pp. 323-360.

[2] Birzer C., and Doolan, C., "Quasi-One-Dimensional Model of Hydrogen-Fueled Scramjet Combustors," Journal of Propulsion and Power, Vol. 25, No. 6, 2009, pp. 1220-1225.

[3] Billig, F., "Research on supersonic combustion,” Journal of Propulsion and Power, Vol. 9, No. 4, 1993, pp. $499-514$.

[4] Li, F., Yu, X. L., Gu, H.,B., Li Z., and Zhao, Y., "Simultaneous measurements of multiple flow Parameters for scramjet Characterization Using Tunable Diode-laser Sensors,” Applied Optics, Vol. 50, No. 36, 2011, pp. 6697-6707.

[5] Micka, D. J., and Driscoll J. F., “Combustion Characteristics of a Dual-Mode Scramjet Combustor with Cavity Flameholder," Proceedings of the Combustion Institute, Vol. 32, No. 2, 2009, pp. 2397-2404. 